\title{
APPLICATION OF RESIDUE CURVE MAP FOR FEASIBILITY ANALYSIS OF EXTRACTIVE DISTILLATION
}

\author{
Sofia Anjum Ahmed \\ Chemical Engineering Department \\ P P Savani University, Kosamba, Gujarat, India
}

\author{
Syed Akhlaq Ahmad \\ Department of Chemical Engineering \\ Aligarh Muslim University, Aligarh, U.P., India
}

\begin{abstract}
A residue curve map (RCM) is a collection of the liquid residue curves in a simple one-stage batch distillation originating from different initial compositions. Computing residue curve maps allows one to find azeotropes and is also considered as powerful tool for the flow-sheet development and preliminary design of conventional multi-component separation processes. Residue curve map has been generated using MATLAB for homogenous azeotropic mixture of acetonechloroform with benzene used as entrainer for extractive distillation. Application of RCM to distillation process has been reported as it not only represents a good approximation to actual equilibrium behavior, but also it allows performing feasibility analysis of separation processes where non-ideal and azeotropic mixtures are involved. However, a generalized and systematic approach is still missing for the feed composition outside conventional compositional ranges which is the aim of study of this paper. The composition simplex obtained from the residue curve map is transformed to sub-regions characterized by separation boundaries and initial separation sequences have been generated. A feasibility analysis of the extractive distillation process has been performed in ASPEN PLUS based upon the location of the feed composition of ternary mixture to obtain high purity acetone and chloroform.
\end{abstract}

Keywords - Extractive Distillation, Residue Curve Map, Feasibility Analysis

\section{INTRODUCTION}

Among the separation processes, distillation is undoubtedly the most widely practiced technique for separating mixtures in the chemical process industries. For the separation of the two components (A and B) forming an azeotrope (close boiling mixtures), a special distillation method must be applied such as the pressure swing distillation (PSD), extractive or azeotropic distillation. You X. et al (2017) studied separation of azeotropic mixtures through energy-saving extractive distillation, Iqbal A. et al (2016) simulated a pressure-swing distillation column for the separation and purification of azeotropic mixtures. One of the most efficient methods of treating an azeotrope is the introduction of an entrainer (mass separation) through the process of azeotropic and/or extractive distillation. Hadler A. B. et al (2009) gave a detailed study of a characteristic composition, temperature and pressure at which the azeotrope exists. Azeotrope either have higher boiling point than its components (called a negative azeotrope) or lower than its components (called a positive azeotrope). Acetone-chloroform mixture is a typical example of a system with a pronounced negative deviation from ideal solution behaviour. This mixture presents a maximum boiling azeotrope with a boiling point of $64.48^{\circ} \mathrm{C}$ and an acetone mole fraction approximately equal to 0.3393 at 1 atm. To separate this azeotropic mixture into pure components, a third component, or entrainer is used which forms a ternary mixture. The vapour-liquid equilibrium behaviour of the resulting ternary mixture can be characterised using residue curve maps (RCM) or distillation line maps (DLM).

A residue curve map (RCM) is a collection of the liquid residue curves in a simple one-stage batch distillation originating from different initial compositions. Computing residue curve maps allows one to find azeotropes as stable nodes, unstable nodes or saddle points. In addition, the residue curve mapping technique (RCM) was considered as powerful tool for the flow-sheet development and preliminary design of conventional multi-component separation processes. Jime'nez L. et al (2001) studied in detail, use of Residue Curve Mapping Technique for the analysis of reactive and extractive distillation simultaneously.

The governing equation to model a simple RCM derived from the Rayleigh Equation that links the liquid mole fraction in the residue $x_{i}$ to the corresponding vapor mole fraction $y_{i}$ has the following final form:

$\frac{d x_{i}}{d x}=x_{i}-y_{i}$

where, $\xi$ is a warped time variable. From equation (1), it appears that pure components and azeotropes are extreme 


\section{International Journal of Engineering Applied Sciences and Technology, 2019 \\ Vol. 4, Issue 2, ISSN No. 2455-2143, Pages 154-159 \\ Published Online June 2019 in IJEAST (http://www.ijeast.com)}

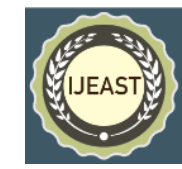

points in the residue curve map since they satisfy the following equation:

$$
x_{i}=y_{i}
$$

If we assume that the deviation from ideal behaviour is only in the liquid phase (low total pressure), we can relate the liquid and vapor mole fractions using the modified Raoult's law,

$$
P y_{i}=x_{i} P_{i}^{s a t} \gamma_{i}
$$

where, $\gamma_{\mathrm{i}}$ is the activity coefficient.

\section{METHODOLOGY}

The non-reactive residue curve map computed for the system by integrating equation (1) forward with dimensionless time $\xi$ from different starting positions i.e. evaporating light components and end at the maximum boiling temperature azeotrope, also integrating equation (1) backward in dimensionless time $\xi$ from the same starting positions i.e. evaporating heavy components and end at the minimum boiling temperature azeotrope. The driving force $\left(x_{i}-y_{i}\right)$ is the difference of the liquid phase $x_{i}$ and vapor phase $y_{i}$ compositions. At the azeotrope, the driving force is equal to zero, because at azeotropic solution $\left(x_{i}=y_{i}\right)$. The integration is continuous until a singular point is reached.

The integration is done using MATLAB ${ }^{\circledR}$ version R2009b software of MathWorks. The strategy used is that the algebraic equations for the vapor-liquid equilibrium and the reaction rate are substituted into the differential equation which is numerically solved by the ode 15 solver in MATLAB. To compute the vapor-liquid equilibrium and since there is deviation from ideality in the liquid phase, an appropriate expressions of the activity coefficients was used. The backward integration of the RCM models is done by transforming the models into its inverse. This way the backward integration can be done the same way as the forward integration. Subsequently, the residue curve maps are obtained by generating multiple residue curves at various starting composition and displaying them together in one figure. By using various initial guesses all singular point can be located. Binous H. et al (2006) developed residue curve maps for Chloroform- Methanol- Acetone system with the help of Mathematica using similar methodology.

\section{A. Thermodynamic Modelling -}

Wilson's model for multi-component mixtures is used as the thermodynamic model for obtaining the activity coefficient for the simulation process. Almeida-Rivera C. et al (2004) established the use of Wilson model for calculating activity coefficient equation due to its accuracy for modeling multicomponent mixtures that do not form two liquids. $\ln \gamma_{k}=-\ln \left(\sum_{j=1}^{m} x_{j} A_{k j}\right)+1-\sum_{i=1}^{m} \frac{x_{i} A_{i k}}{\sum_{j=1}^{m} x_{i} A_{i j}}$

In equation (4), $\mathrm{A}_{\mathrm{ij}}$ is the binary interaction parameter which depends on the molar volumes $\left(v_{i}\right.$ and $\left.v_{j}\right)$ and the energy terms $\lambda_{\mathrm{ii}}$ and $\lambda_{\mathrm{ij}}$

$A_{i j}=\frac{V_{j}^{j}}{V_{i}} \exp \left(-\frac{\partial_{i j}-\lambda_{i i n}}{R T}\right)$

The vapor pressure $P_{\mathbb{i}}^{\text {vat }}$ is obtained using Antoine's equation,

$\ln P_{\mathrm{i}}^{\text {vat }}=A_{\mathrm{i}}-\frac{B_{\mathrm{i}}}{C_{\mathrm{i}}+T}$

The VLE experimental data for acetone-chloroform, acetone-benzene and chloroform-benzene have been obtained from Dortmund data bank and regressed and optimized to obtain a new set of binary interaction parameters as shown in Table 1.

Table-1: Wilson model binary interaction parameters for acetonechloroform-benzene system

\begin{tabular}{|c|c|c|c|}
\hline$C_{i}$ & Acetone & Acetone & Chloroform \\
\hline$C_{j}$ & Chloroform & Benzene & Benzene \\
\hline$\Lambda_{\mathrm{ij}}$ & $\mathbf{1 1 6 . 1 1 7}$ & $\mathbf{6 8 2 . 4 0 6 1}$ & $\mathbf{- 7 1 . 8 1 0 8 9}$ \\
\hline$\Lambda_{\mathrm{ji}}$ & $\mathbf{- 5 0 6 . 8 5 1}$ & $\mathbf{- 2 4 3 . 9 6 5 1}$ & $\mathbf{- 1 1 . 8 2 1}$ \\
\hline
\end{tabular}

\section{B. Case Study -}

This example addresses the separation of a mixture of acetone and chloroform, in which components form a maximum-boiling azeotrope. Benzene is used as a promising entainer to break the azeotrope and obtain pure compounds. Sutijan et al (2012) presented methodology for automatic selection of entrainers for separating binary azeotropic mixtures using homogeneous azeotropic distillation. The binary feed mixture, which contains 60 mole $\%$ acetone and 40 mole \% chloroform, is to be purified using homogeneous extractive distillation. Since the azeotrope composition is pressure-insensitive, binary pressure-swing distillation is not a cost-effective design option. An entrainer is needed to facilitate the separation. Since the binary feed is richer in acetone than chloroform, acetone is selected as the primary product. Residue curve map at 1 atm for the given ternary mixture is developed using the MATLAB code and is as shown in the figure 1 . The composition, temperature and stability of singular points and existence and termini of distillation boundary is obtained from the residue curve map which is the output of the program.

All residue curves in the figure either start in the pure component acetone or chloroform vertex and end in pure benzene. This is due to the fact that acetone is low boiling component and benzene is the high boiling component and all the residue curves start at low boiling component and ends up 


\section{International Journal of Engineering Applied Sciences and Technology, 2019 \\ Vol. 4, Issue 2, ISSN No. 2455-2143, Pages 154-159 \\ Published Online June 2019 in IJEAST (http://www.ijeast.com)}

at the high boiling component. A distillation boundary appears at a binary azeotrope of acetone-chloroform at $64.48^{\circ} \mathrm{C}$ hence dividing the residue curve map in two regions. This makes pure acetone and chloroform unstable nodes and pure benzene as a stable node and the binary azeotrope is a saddle point in the system. The presence of the binary acetone/chloroform azeotrope makes that the RCM is divided into two distillation regions which are separated by the distillation boundary between the binary azeotrope and the pure component benzene vertex. The concept of nodes, saddles and distillation line maps were studied in detail in the work proposed by Stichlmair J. G. et al (1992).

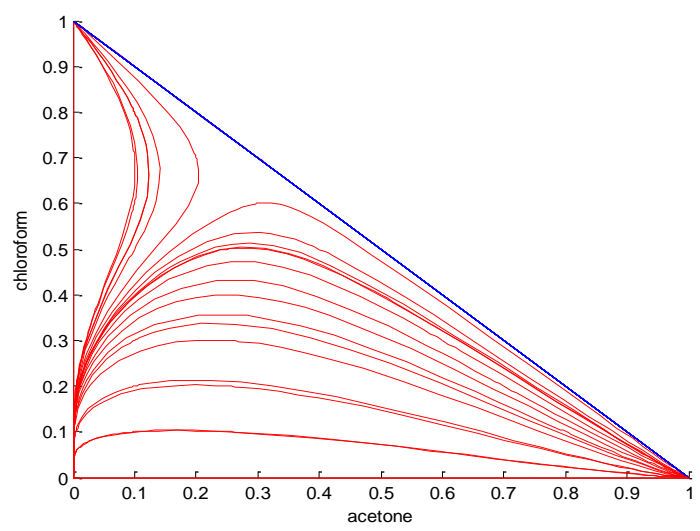

Watermark Extraction algorithm Block Diagram

Fig. 1. Output of the program: RCM of acetone-chloroform system with benzene as entainer at $1 \mathrm{~atm}$.

\section{FEASIBILITY ANALYSIS \& SEQUENCE COMPOSITION}

A clearer representation of the reactive system is possible when the conventional residue curve map is represented with a distillation boundary.

As shown in the figure 2, the composition simplex is divided into two well-defined regions:

- Region I: residue curves that start at pure chloroform and end at pure benzene corner with a saddle point at the binary azeotrope.

- Region II: residue curves that start at pure acetone and end at pure benzene corner with a saddle point at the binary azeotrope.

Thus, the separation sequences may differ depending upon the location of the feed in the composition simplex. The feed containing 60 mole\% acetone and 40 mole\% chloroform lie in the region II and the two sequence separation can be obtained.

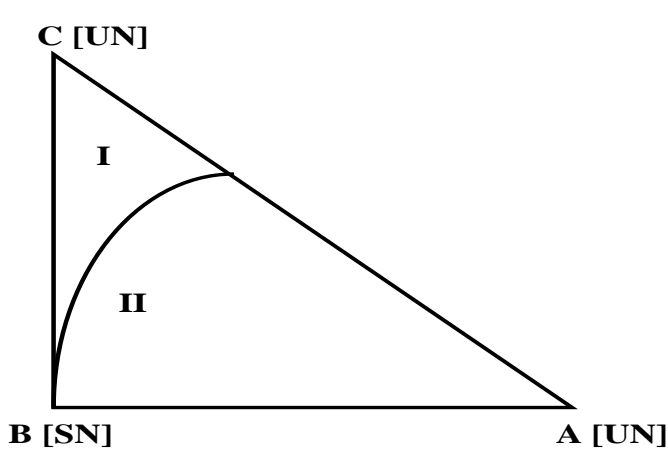

Fig. 2. Schematic representation of the distillation boundary for the separation of acetone-chloroform at $1 \mathrm{~atm}$.

\section{A. Case-I: Separation with boundary crossing -}

Boundary crossing by distillation can be demonstrated as follows. Suppose that we have an RCM with a single (extremely) curved distillation boundary and if the feed composition $(\mathrm{F})$ is located close enough to the concave side of the boundary as is the case with our feed mixture, a distillation column balance line may give us top and bottoms products that are located on the same RC (as required) but with the feed and the products on opposite sides of the distillation boundary. Fien G. et al (1994) presented a review on heuristic synthesis and shortcut design of separation processes using residue curve maps. However, if the distillation boundary is curved, the steady state composition profile in a continuous distillation column cannot cross the boundary from the convex side but may cross the boundary from the concave side when moving from the product compositions outward. The above case is simulated in ASPEN PLUS v.8.8 to obtain the desired results and the generated sequence is depicted in figure 3 .

The sequence for the following operation (figure 3 ) is stated as follows:

- the feed F (Acetone:Chloroform) is mixed with the recycle stream from $\mathrm{C}-2$ to obtain the feed mixture $\mathrm{M}$,

- $\mathrm{M}$ is fed to column $\mathrm{C} 1$ and separated into distillate D1 (pure acetone) and bottoms B1,

- B1 enters column C2 and is divided into the stream D2 (pure chloroform) and the recycle stream B2 (since the distillation boundary is curved, the distillation balance line is able to cross the boundary). 


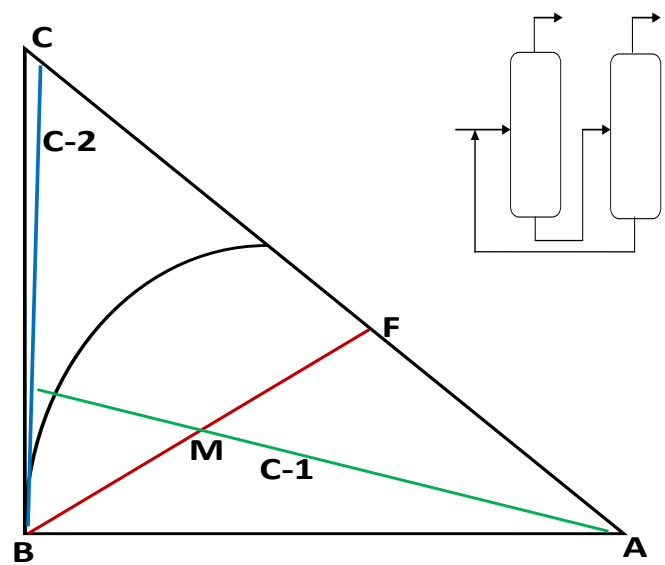

Fig. 3. Two column flowsheet with boundary crossing

\section{B. Case-II: Separation with boundary shifting -}

Boundary shifting method is based on the determination of feasible compositions of products (continuously withdrawn) and those of bottom by analysis of the residue curves in the RCM at two different pressures as shown in figure 4.The feasible region (FR) of the separation is defined as follows: All feed compositions from where all three components (or two components at the binary system) can be purely recovered by maximal separation (in at least one appropriate one- or two-column configuration) at the given pressure or by the application of pressure swing. (The number of separation steps is not limited). This concept was earlier established by Fien $\mathrm{G}$. et al (1994). The operating region of pressure-swing distillation is defined as follows: All feed compositions from which, through pressure changes, the different components can be purely recovered by maximal separation. Similar work was simulated in ASPEN Plus by Lyuben W. (2008) and dynamic simulation showed best separation for different pressure ranges. This process is similar to pressure swing distillation. But, in this case, an entrainer is introduced. Higher pressure differences increase the gap between the two boundaries. As acetone-chloroform system is pressure insensitive system the boundary shifting case is infeasible to simulate and hence is not presented in this study.

The sequence involves the following operations (Figure 4) is as follows:

- the feed F (Acetone:Chloroform) is mixed with the recycle stream from $\mathrm{C}-2$ and $\mathrm{C}-3$ to obtain the feed mixture $\mathrm{M}$,

- $\mathrm{M}$ is fed to column $\mathrm{C} 1$ and separated into distillate D1 (pure acetone) and bottoms B1,

- B1 enters column C2 and is divided into the stream D2 and the recycle stream B2 (since the boundary crossing occurs column C-2 is at a higher pressure than column C1),

- D2 enters column C3 and is divided into the stream D3 (pure chloroform) and the recycle stream B3.

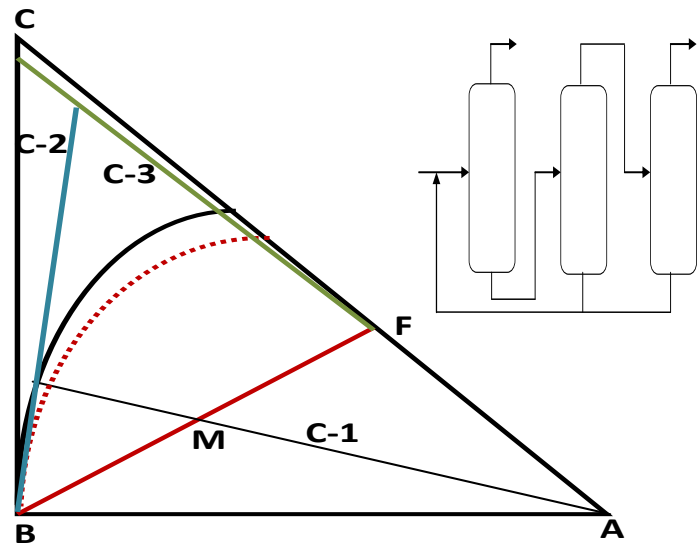

Fig. 4. Three column flowsheet with boundary shifting

\section{PROBLEM DESIGN \& SPECIFICATION}

In extractive distillation, the added component (solvent) modifies the relative volatility of the original components and causes the azeotropic point to disappear. Chien I. L. et al (1999) analyzed steady state process $\mathrm{IPA}+\mathrm{H}_{2} \mathrm{O}+\mathrm{CyH}$ azeotrope which showed that the optimal separation point must be under the distillation boundary curve range. In this study, the heavy boiling entrainers (benzene) were used, thus have the highest boiling point amongst all other components thereby coming out from the bottom of the solvent recovery column. The operating conditions for the process simulation have been listed in Table 2 .

Table-2: Operating conditions for the process simulation

\begin{tabular}{|c|c|c|}
\hline $\begin{array}{l}\text { Unit } \\
\text { Tag }\end{array}$ & Description & Operating Parameter \\
\hline C-1 & $\begin{array}{c}\text { First } \\
\text { Column } \\
\text { (Extractive } \\
\text { Column) }\end{array}$ & $\begin{array}{l}\text { - Operating Pressure: } 1.1 \text { atm } \\
\text { - Number of tray: } 50 \\
\text { - Light Key Component: Acetone } \\
\text { - Light Key Component Purity: } 0.98\end{array}$ \\
\hline C-2 & $\begin{array}{l}\text { Second } \\
\text { Column } \\
\text { (Solvent } \\
\text { Recovery } \\
\text { Column) }\end{array}$ & $\begin{array}{l}\text { - Operating Pressure: } 1.1 \mathrm{~atm} \\
\text { - Number of tray: } 20 \\
\text { - Light Key Component: Chloroform } \\
\text { - Light Key Component Purity: } 0.98\end{array}$ \\
\hline $\mathbf{F}$ & $\begin{array}{c}\text { Feed } \\
\text { Stream }\end{array}$ & $\begin{array}{l}\text { - Molar Flowrate: } 100 \mathrm{kmol} / \mathrm{hr} \\
\text { - Molar Composition (mole fraction) : } \\
\text { Acetone: } 0.6 \\
\text { Chloroform: } 0.4\end{array}$ \\
\hline
\end{tabular}

Figure 5 describes the process flow diagram generated in ASPENPLUS v8.8 for the separation of acetonechloroform-entrainer system in which the azeotropic mixture 


\section{International Journal of Engineering Applied Sciences and Technology, 2019 \\ Vol. 4, Issue 2, ISSN No. 2455-2143, Pages 154-159 \\ Published Online June 2019 in IJEAST (http://www.ijeast.com)}

and the solvent are fed to the 1st column wherein the acetone (lowest boiling point component) comes as the top product while chloroform along with the entrainer comes as bottom product. The bottom stream is then fed to the 2 nd column to recover the solvent from the bottom while chloroform comes out from the top. A small amount of make-up stream is fed to the system to make-up the solvent loss.

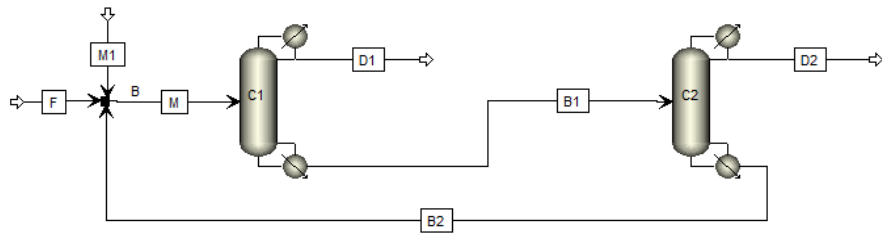

Fig. 5. Process flow diagram for the extractive distillation of acetonechloroform-Benzene

\section{RESULTS}

A study for the separation of the acetone-chloroform system has been made using benzene as a solvent. In this study, optimum solvent flow rate is set at $7 \mathrm{kmol} / \mathrm{hr}$ to give maximum separation of acetone-chloroform mixture. The top product is acetone from column $\mathrm{C}-1$ having mole fraction 0.756 mole fraction and recovery of acetone is $81 \%$. The top product of column $\mathrm{C}-2$ is chloroform with 0.763 mole fraction which is $83 \%$ recovery from the feed mixture. The bottom product of column C-2 is benzene with the recovery of $87 \%$. Higher solvent flow rate leads to higher acetone purity. However, at higher solvent flowrate the recovery of chloroform in the second column is reduced because of the presence of benzene in the top product mixture. The result of simulation studies is shown in the Table 3.

Table-3: Optimized results for the overall process

\begin{tabular}{|c|c|c|}
\hline $\begin{array}{l}\text { Unit } \\
\text { Tag }\end{array}$ & Description & Output value \\
\hline C-1 & $\begin{array}{c}\text { First Column } \\
\text { (Extractive } \\
\text { Column) }\end{array}$ & $\begin{array}{l}\text { - Top product : } \\
\text { Acetone }=58.8 \mathrm{kmol} / \mathrm{hr}(0.756 \text { mole fraction }) \\
\text { - Bottom product : } \\
\text { Chloroform }=0.20 \text { mole fraction } \\
\text { - D/F ratio: } 0.65 \\
\text { - Reflux ratio: } 0.50\end{array}$ \\
\hline C-2 & $\begin{array}{c}\text { Second } \\
\text { Column } \\
\text { (Solvent } \\
\text { Recovery } \\
\text { Column) }\end{array}$ & $\begin{array}{l}\text { - Top product : } \\
\text { Chloroform }=33.20 \mathrm{kmol} / \mathrm{hr}(0.763 \text { mole } \\
\text { fraction }) \\
\text { - Bottom product : } \\
\text { Benzene }=37.58 \mathrm{kmol} / \mathrm{hr}(0.99 \text { mole fraction }) \\
\text { - D/F ratio: } 0.572 \\
\text { - Reflux ratio: } 0.83\end{array}$ \\
\hline
\end{tabular}

\section{CONCLUSION}

In this study, residue curve map is generated and used as a tool in designing feasible extractive distillation scheme to obtain products of maximum purity for a given feed mixture. An extractive distillation for the separation of acetonechloroform (maximum boiling) azeotrope using benzene as solvent is studied. For the acetone-chloroform separation, using the RCM two main sub-regions have been defined by singular points (nodes and saddles) and limited by separation boundaries.Two separation strategies have been identified: (i) Boundary Crossing and (ii) Boundary Shifting. The case of boundary crossing have been simulated and studied. In the generated sequence, high purity solvent from the solvent recovery column as bottom product is recycled back to the first column. The top product of $\mathrm{C}-1$ is acetone with $0.78 \mathrm{~mol}$ fraction and the top product of $\mathrm{C}-2$ is chloroform with 0.76 mol fraction.

\section{REFERENCE}

[1] You X. (2017) 'Improved design and optimization for separating azeotropes with heavy component as distillate through energy-saving extractive distillation by varying pressure`. Industrial \& Engineering Chemistry Research, DOI: 10.1021/acs.iecr.7b00687.

[2] Iqbal A. and Ahmad S. A. (2016) 'Pressure swing distillation of azeotropicmixture - A simulation study`. Perspectives in Sciences, PISC-136, (pp. 1-3).

[3] Hadler A. B. Ott L. S. and Bruno T. J. (2009) 'Study of azeotropic mixtures with the advanced distillation curve approach`. Fluid Phase Equilibria, vol. 281, (pp. 49-59).

[4] Jime'nez L., Wanhschafft O. M., Julka V. (2001). 'Analysis of residue curve maps of reactive and extractive distillation units`. Computers and Chemical Egineering, vol. 25, (pp. 635-342).

[5] Binous H., Wakad A. and Achour S. B. (2006). 'Residue curve map calculation of a ternary mixture`Computers in Educational Journal; (pp. 32-35).

[6] Almeida-Rivera C. and Grievink J. (2004). 'Feasibility of equilibrium controlled reactive distillation process: application of residue curve mapping` Computers and Chemical Engineering; vol. 28, (pp. 17-25).

[7] Sutijan, Jobson M. and Smith R. (2012). 'Synthesis of Ternary Homogeneous Azeotropic Distillation Sequences: Entrainer Selection`. AJCHE, vol. 12, (pp. 20-33).

[8] Stichlmair J. G. and Herguijuela J-R. (1992) 'Separation and Regions and Processes of Zeotropic Azeotropic Ternary Distillation`. AICHE Journal, vol. 38, (pp. 15231535).

[9] Fien G. and Liu Y. (1994). 'Heuristic synthesis and shortcut design of separation processes using residue curve maps: a review Industrial and Engineering Chemistry Research, vol. 33, (pp. 2505-2522). 
[10] Luyben W. (2008). 'Control of the Maximum-Boiling Acetone/Chloroform Azeotropic Distillation System`Ind. Eng. Chem. Res., vol. 47, (pp. 6140-6149).

[11] Chein I. N., Wang C. H. and Wong D. S. H. (1999). 'Dynamics and Control of a Heterogeneous Azeotropic Distillation Column: Conventional Control Approach . Ind. Eng. Chem. Res, vol. 38, (pp. 468-478). 